\title{
Application of synchrotron-radiation-induced TXRF-XANES for arsenic speciation in cucumber (Cucumis sativus L.) xylem sap
}

\author{
F. Meirer, ${ }^{1 *}$ G. Pepponi, ${ }^{2}$ C. Streli, ${ }^{1}$ P. Wobrauschek, ${ }^{1}$ V. G. Mihucz, ${ }^{3}$ G. Záray, ${ }^{3}$ V. Czech, ${ }^{4}$ \\ J. A. C. Broekaert, ${ }^{5}$ U. E. A. Fittschen ${ }^{5}$ and G. Falkenberg ${ }^{6}$
}

\author{
${ }^{1}$ Atominstitut, Vienna University of Technology, 1020 Wien, Austria \\ 2 ITC-irst, via Sommarive 18, 38050 Povo (Trento) Italy \\ ${ }^{3}$ Joint Research Group of Environmental Chemistry of Hungarian Academy of Sciences and L. Eötvös University, Budapest, Hungary \\ ${ }^{4}$ Department of Plant Physiology, L. Eötvös University, Budapest, Hungary \\ ${ }^{5}$ Department of Chemistry, University of Hamburg, 20146 Hamburg, Germany \\ ${ }^{6}$ Hamburger Synchrotronstrahlungslabor at DESY, 22607 Hamburg, Germany
}

Received 30 March 2007; Revised 20 June 2007; Accepted 16 July 2007

\begin{abstract}
Synchrotron-radiation-induced total reflection x-ray fluorescence (SR-TXRF) analysis was used for $x$-ray absorption near edge structure (XANES) measurements for the speciation of arsenic in cucumber (Cucumis sativus L.) xylem sap. The objective of the presented work was to exploit the advantages of the TXRF geometry for XANES analysis. Measurements were accomplished at the bending magnet beamline $\mathrm{L}$ of HASYLAB, Hamburg, Germany, using a Si(111) double crystal monochromator and a silicon drift detector (SDD). Experiments were performed by growing cucumber plants in hydroponics containing arsenite [As(III)] or arsenate [As(V)] in order to identify the arsenic species of the collected xylem saps by K-edge SR-TXRF XANES. Cucumber xylem saps, as well as nutrient solutions containing arsenic in the two above-mentioned species, were analyzed and compared with arsenate and arsenite standard solutions. Arsenic speciation in xylem sap down to $30 \mathrm{ng} / \mathrm{ml}(30 \mathrm{ppb})$ was achieved, and no alteration of the oxidation state was observed during the measurements. Analysis of xylem saps showed that As(V) taken up from the nutrient solution was reduced to As(III). As(III) contained in the nutrient solutions was found to be partially oxidized to As(V). These results confirmed the preliminary measurements obtained with flow injection analysis (FIA) and high-performance liquid chromatography-high resolution inductively coupled plasma mass spectrometry (HPLC-HR-ICP-MS) and showed the competitive capability of SR-TXRF XANES analysis for this application. Copyright @ 2007 John Wiley \& Sons, Ltd.
\end{abstract}

\section{INTRODUCTION}

Synchrotron-radiation-induced total reflection x-ray fluorescence (SR-TXRF) offers detection limits in the femtogram range for transition metals with a multilayer monochromator and a bending magnet beamline. ${ }^{1-4}$ If a crystal monochromator is used instead of a multilayer, the technique can be extended to $x$-ray absorption measurements to gain chemical information on a specific element of interest. ${ }^{4-8}$ Owing to the fact that the flux delivered by a crystal monochromator (e.g. $\mathrm{Si}(111))$ is about two orders of magnitude lower than the one from a multilayer, one has a lower sensitivity for x-ray fluorescence analysis. However, this modified setup still offers sufficient sensitivity for elemental analysis at the nanogram per milliliter ( $\mathrm{ppb}$ ) level. Furthermore, it allows the extension of XAS to the trace element level in droplet samples, where only small amounts are available ${ }^{4,5}$ and even in the low energy range, but by using a plane grating monochromator. ${ }^{9}$

Various publications describing the method of $x$-ray absorption analysis for the speciation of arsenic in samples with As concentrations in the ppm range can be found

*Correspondence to: F. Meirer, Atomic Institute, Vienna University of Technology, Stadionallee 2, A-1020 Vienna, Austria.

E-mail: fmeirer@ati.ac.at in the literature. ${ }^{10-14}$ However, previous investigation of the cucumber xylem saps with flow injection analysis (FIA) and high-performance liquid chromatography-high resolution inductively coupled plasma mass spectrometry (HPLC-HRICP-MS) revealed arsenic concentrations in the 30-50 ng/ml (ppb) range, ${ }^{15}$ which can be analyzed by SR-TXRF. Therefore the applicability of $\mathrm{x}$-ray absorption near edge structure (XANES) with TXRF acquisition for the determination of the arsenic species in cucumber xylem saps was tested in this work.

An important point in elemental speciation is to avoid chemical transformation of the samples during the analysis; therefore it is of great advantage if only minimal sample preparation is necessary. SR-TXRF allows analyses of xylem saps directly after collection with micropipettes in an argon atmosphere without any further sample preparation. Additionally only few microliters of solutions are required for TXRF measurements, ${ }^{1-5}$ which is another advantage for the analysis of xylem saps.

The speciation of arsenic in xylem saps is relevant because the toxicity of arsenic differs considerably depending on the oxidation state and chemical form. Inorganic species, such as arsenite and arsenate, are more toxic than the 
organic ones, e.g. monomethyl arsonic (MMA) and dimethyl arsinic (DMA) acids. ${ }^{16,17}$ Arsenite is generally more toxic than arsenate ${ }^{15-17}$ and reacts with sulfhydryl groups of enzymes and tissue proteins, leading to inhibition of cellular function and death. ${ }^{18,19}$ In the case of plants, arsenate acts as an analog of phosphate, competing for the same uptake carriers in the root. ${ }^{18,20,21}$ It has been shown ${ }^{15,17,20,22}$ that plants have the capability to change the oxidation state of arsenic. Research focuses on xylem sap, because the plant xylem is primarily responsible for transportation of water and solutes. Furthermore, only minimal sample preparation is required as the xylem sap can be easily collected and only ancillary filtration has to be done. ${ }^{15,23}$

To understand how (edible) plants metabolize and transform arsenic is essential for mainly two reasons: first of all plants can be used as indicators for the bioavailable part of arsenic in soil, and, second, the remaining arsenic in plants is available to the next level in the food chain.

In the southeastern part of Hungary arsenic is a known contaminant in groundwater which can reach concentrations up to $150 \mathrm{ng} / \mathrm{ml}^{15,20,24}$ The World Health Organization (WHO) recommends an upper limit of $10 \mathrm{ng} / \mathrm{ml}$ for arsenic in drinking water. ${ }^{25}$ The inorganic species arsenate and arsenite are the predominant form of arsenic in terrestrial plants, whereas organic species like DMA and MMA have only been found in relatively low concentrations. ${ }^{18}$ Therefore nutrient solutions containing arsenite and arsenate and standard samples of this two arsenic species were used in the presented work.

\section{EXPERIMENTAL}

Plant growth and sampling was done at the Plant Physiology Department of Eötvös University of Budapest. ${ }^{15}$ Cucumber plant seedlings were grown in a modified Hoagland solution. At two leaf stage the plants were transferred to nutrient solutions containing $150 \mathrm{ng} / \mathrm{ml} \mathrm{As(V)}$ or As(III). After 14 days of this arsenic treatment, xylem sap was collected from the stem of the plants, deposited on quartz reflectors and dried. Prior to the xylem sap collection, plants were kept in arsenic-free nutrient solutions containing double concentration of $\mathrm{KNO}_{3}$ with respect to the primary Hoagland solution for $1 \mathrm{~h}$ in order to enhance bleeding. Xylem sap was collected with micropipettes from groups of four plants for $15 \mathrm{~min}$ in an argon atmosphere and transferred into PE vials immersed in an ice-salt bath. The mass of xylem sap collected from plants treated with $\mathrm{As}(\mathrm{III})$ and $\mathrm{As}(\mathrm{V})$ was determined to be 382 and $430 \mathrm{mg}$, respectively.

Standard solutions containing arsenic in concentrations of $10 \mu \mathrm{g} / \mathrm{ml}$ were prepared for both arsenic species. From these solutions standard samples were prepared with different arsenic mass by pipetting 1 and $20 \mu \mathrm{l}$ (4 times $5 \mu \mathrm{l}$ ) onto quartz reflectors. In the case of nutrient solutions and xylem saps, volumes of 10 and $20 \mu \mathrm{l}$ (4 times $5 \mu \mathrm{l}$ ) were applied. After the deposition, the samples were vacuumdried for 3-5 min and transported in an inert atmosphere (Ar) in order to prevent oxidation.

Mihucz et al. ${ }^{15}$ observed a partial oxidation of the arsenite to arsenate in the case of arsenite-containing nutrient solutions. To cross-check this observation, samples were taken from the As(III)-containing nutrient solutions $48 \mathrm{~h}$ after the plants were placed in these solutions.

Arsenic K-edge XANES measurements in the fluorescence mode and grazing incidence geometry were carried out using the setup at the Beamline L at the Hamburger Synchrotronstrahlungslabor (HASYLAB) at DESY., ${ }^{46}$ Shortly before measurement, the specimen were taken out of the protective atmosphere and placed in the vacuum chamber of the spectrometer. All measurements were performed in vacuum. A Si(111) double crystal monochromator was used for selecting the energy of the exciting beam from the continuous $\mathrm{x}$-ray spectrum emitted by the $1.2 \mathrm{~T}$ bending magnet at Beamline L. The primary beam was collimated to $200 \times 1400 \mu \mathrm{m}$ (horizontal $\times$ vertical) by a cross-slit system. The incident $x$-ray intensity was monitored with the aid of an ionization chamber.

During the measurements, the excitation energy was tuned in varying steps $(5-0.5 \mathrm{eV})$ across the arsenic K-edge at $11862 \mathrm{eV}$. At each energy, a fluorescence spectrum was recorded by a silicon drift detector (SDD), (VORTEX $50 \mathrm{~mm}^{2}$, Radiant Detector Technologies). ${ }^{27,28}$ The distance between the SDD and the sample carrier was ${ }^{4} 1 \mathrm{~mm}$. The acquisition time for each spectrum was set to 5 (or 3 ) s for standard and nutrient solutions and $20 \mathrm{~s}$ for the xylem sap samples. For each scan 280 spectra were recorded. For each specimen not less than three repetitive scans were performed.

The critical angle for total reflection changes during an energy scan. In the particular case, the critical angle of silicon shifts from 2.67 to 2.56 mrad for an energy variation from 11700 to $12200 \mathrm{eV}$. On that account the incident angle of the primary $x$-ray beam was adjusted to $2 \mathrm{mrad}$, which is far below the critical angle, and it can be assumed that the change of the critical angle during the XANES scans is unproblematic for the measurement of droplet samples (residues on the surface).

At least two specimen were analyzed for all six different types of samples [As(V) and As(III) standards, As(V)and As(III)-containing nutrient solutions and xylem saps collected from plants grown in As(V)- and As(III)-containing nutrient solutions].

Simultaneously, the absorption by an elemental gold foil was recorded in transmission mode. The first inflection point (i.e. the first maximum of the derivative spectrum) of the $\mathrm{Au}$ metal foil scan was assumed to be $11918 \mathrm{eV}$ (Au L3 edge).

For quantification, single fluorescence spectra recorded at $12200 \mathrm{eV}$ (Fig. 1) were evaluated using the Quantitative x-ray Analysis System (QXAS) software package. ${ }^{29}$ The arsenic concentrations in the xylem sap samples were calculated from sensitivities obtained by the measurements of the standard samples.

Absorption spectra have been analyzed within ATHENA which is included in the IFEFFIT program package for XAFS analysis. ${ }^{30-32}$ The background removal of the As K-edge profiles was done by the implemented AUTOBK algorithm and normalization was performed by edge step normalization ${ }^{32}$ using a pre-edge region ranging from -150 to $-30 \mathrm{eV}$. For each scan, the energy scale was corrected with respect to the Au-L3 edge. Multiple scans of the same sample have been merged by calculating the average and 


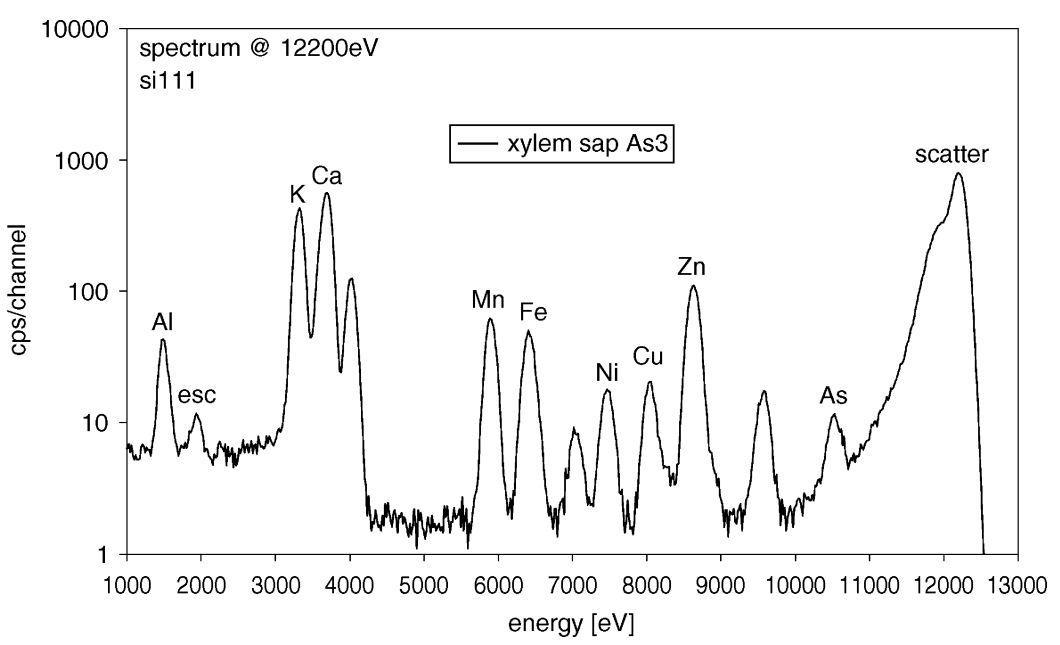

Figure 1. Fluorescence spectrum of xylem sap recorded at $12200 \mathrm{eV}$.

standard deviation at each point in the set and scans of the xylem sap samples were smoothed by the removal of spurious points. A linear combination analysis of the K-edge profiles was carried out with the fitting method of ATHENA. Linear combinations of the near-edge spectra for the standard solutions were fitted to those of the xylem sap samples. The fitting range was set from -20 to $+50 \mathrm{eV}$ relative to the edge and each fit included 96 data points and 1 variable. The same parameters were used for fitting the spectra of nutrient solution samples.

\section{RESULTS AND DISCUSSION}

Quantification of the xylem sap samples revealed arsenic concentrations in the range of 30 to $50 \mathrm{ng} / \mathrm{ml}$ corresponding to an amount of $0.6-1 \mathrm{ng}$ for the samples where $20 \mu \mathrm{l}$ was pipetted. A representative spectrum obtained from a $20 \mu \mathrm{l}$ xylem sap sample is given in Fig. 1.

Detection limits for arsenic in xylem sap were determined by extrapolation for a $1000 \mathrm{~s}$ measuring time and found to be in the $0.2 \mathrm{ng} / \mathrm{ml}$ range. These results are in good agreement with the ones obtained with FIA, which showed total arsenic concentrations of $29.5 \pm 1$ and $45.7 \pm 2.6 \mathrm{ng} / \mathrm{ml}$ in xylem saps of plants treated with $\mathrm{As}(\mathrm{V})$ and As(III), respectively. ${ }^{15}$

Multiple scans of each sample were analyzed to confirm the reproducibility of the measurements and to check if any alteration of the oxidation state occurred during the measurement. Figure 2 shows two examples of four repetitive XANES scans. In case of the nutrient solution the total measuring time was $100 \mathrm{~min}$ ( $25 \mathrm{~min}$ each). For the standard sample, the time was $220 \mathrm{~min}$ ( $55 \mathrm{~min}$ each). It is obvious from the plots that no edge shifts or changes in the oscillatory part of the spectra appeared during the measuring time. Therefore it can be concluded that the chemical state of the sample remained unchanged during the measurements.

Normalized As K-edge profiles for xylem sap samples, nutrient solution samples and reference As standard samples are shown in Fig. 3. The spectra are displaced vertically for clarity. The vertical dotted line indicates the energy of the $\mathrm{Au}$ L3 edge used for energy calibration. The vertical solid line marks the white line (strongest absorption peak) of the As(III) standard spectrum to visualize the edge shifts. The two xylem profiles labeled 'xylem sap (As(III))' and 'xylem sap (As(V))' refer to samples collected from plants treated with nutrient solutions containing As(III) and As(V), respectively. The plot shows that the spectra of these two types of xylem samples have the same edge position, which furthermore coincides with the edge position of the As(III) standard. These results indicate that $\mathrm{As}(\mathrm{III})$ is the predominant form in xylem saps, although the plants had been grown in nutrient solutions containing different arsenic species. The XANES spectrum of the As(III) nutrient solution collected $48 \mathrm{~h}$ after the start of the arsenic treatment shows an energy shift towards the $\mathrm{As}(\mathrm{V})$ edge position. This indicates a partial oxidation of $\mathrm{As}(\mathrm{III})$ to $\mathrm{As}(\mathrm{V})$ during this time period.

All XANES spectra of nutrient solutions and xylem saps have been fitted with linear combinations of the spectra of the $\mathrm{As}(\mathrm{III})$ and $\mathrm{As}(\mathrm{V})$ standards. Table 1 shows the results of the processed fits and the quality-of-fit parameter, reduced chi square. The results give quantitative information about the findings discussed qualitatively in Fig. 3. More than $80 \%$ of the arsenic in the xylem sap was found to be As(III) independent of the arsenic treatment. Mihucz et al. ${ }^{15}$ reported $86 \%$ As(III) in xylem saps which is in good agreement with these results. After $48 \mathrm{~h},<30 \%$ of the As(III) in nutrient solutions was oxidized to $\mathrm{As}(\mathrm{V})$.

Table 1. Results of best linear combination fits for spectra of standard samples to those for xylem sap and nutrient solution samples

\begin{tabular}{lcccc}
\hline & & & Reduced \\
Sample & $\begin{array}{c}\% \\
\text { chi }\end{array}$ & $\begin{array}{c}\text { chi } \\
\text { As(III) }\end{array}$ & $\begin{array}{c}\text { As(V) } \\
\text { square }\end{array}$ & square \\
\hline xylem sap (As(III)) & 88 & 12 & 0.0115 & 1.09 \\
xylem sap (As(V)) & 83 & 17 & 0.0112 & 1.06 \\
As(III) nutrient solution & 100 & 0 & 0.0072 & 0.68 \\
As(III) nutrient solution & 71 & 29 & 0.0063 & 0.60 \\
after 48h & & & & \\
As(V) nutrient solution & 2 & 98 & 0.0066 & 0.63 \\
\hline
\end{tabular}

a The results given here are taken from the analysis of individual specimens; therefore no statistical uncertainty could be calculated. Estimated uncertainties are given in the text. 

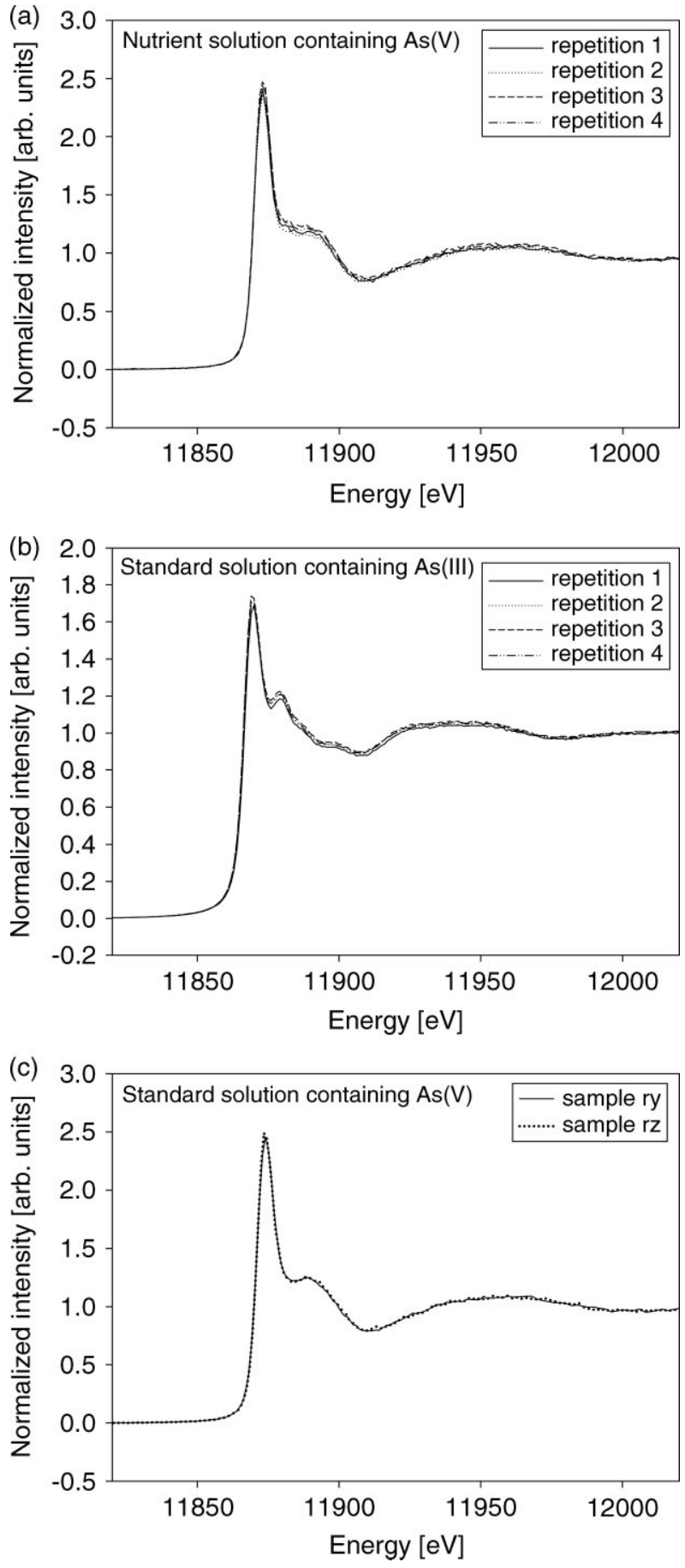

Figure 2. Repetitive XANES scans of two samples: (a) $10 \mu \mathrm{l}$ of nutrient solution containing $750 \mathrm{ng} / \mathrm{ml} \mathrm{As}(\mathrm{V})$ and (b) $20 \mu \mathrm{l}$ of $10 \mu \mathrm{g} / \mathrm{ml}$ As(III) standard solution. Figure 2(c)) shows two scans of samples applied to different quartz reflectors using the same standard solution $(1 \mu \mathrm{l}$ of $10 \mathrm{ppm}$ As(V)).

To estimate an uncertainty for the fitting results, repetitive scans of the same sample were fitted individually to determine the influence of the measurement statistics. The uncertainty of the $\mathrm{As}(\mathrm{V}) / \mathrm{As}(\mathrm{III})$ ratio determination was found to be $2 \%$ for the fitting of the spectra of nutrient solutions and $5 \%$ for the fitting of xylem saps.

During the measurements of the higher concentrated standard samples a damping of the white-line was observed.

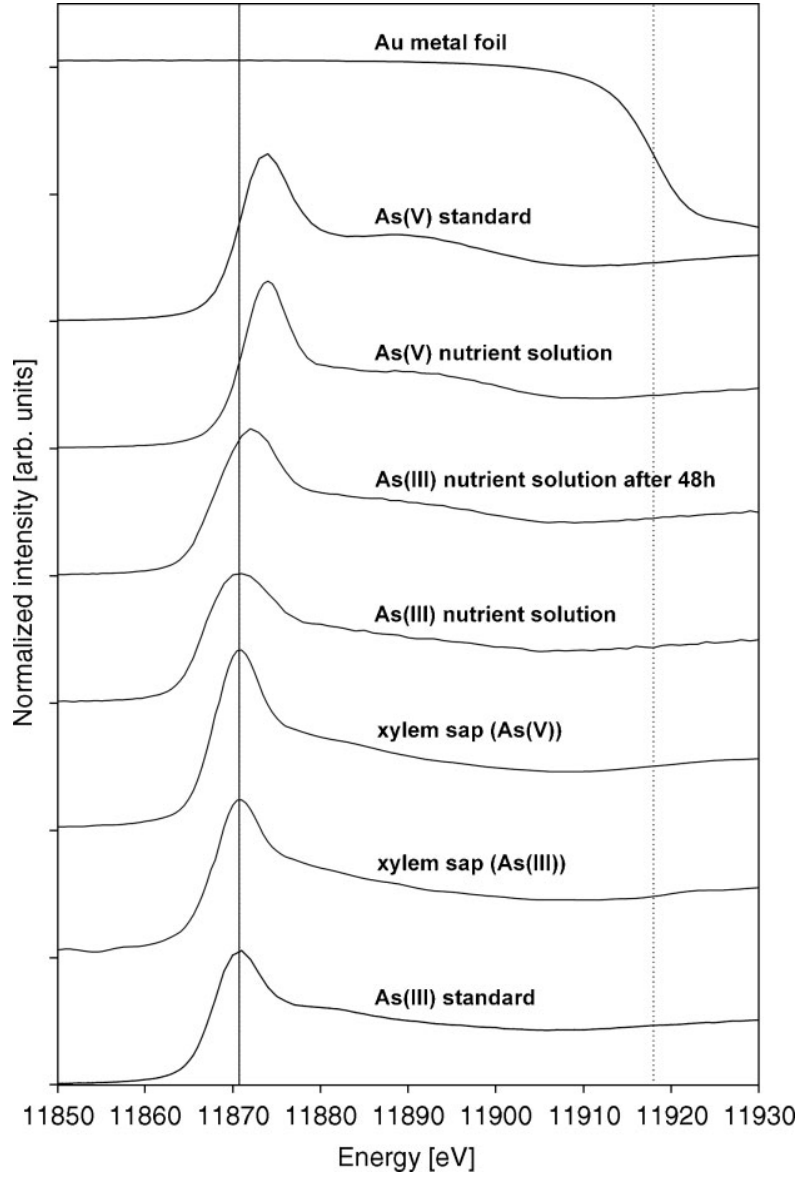

Figure 3. Normalized arsenic K-edge XANES spectra for the xylem sap, the nutrient solution and the As reference samples.

Figure 4 shows this effect on the basis of two XANES scans recorded for two $\mathrm{As}(\mathrm{V})$ standard samples made from the same standard solution containing $10 \mu \mathrm{g} / \mathrm{ml} \mathrm{As}(\mathrm{V})$. Different volumes of $1 \mu \mathrm{l}$ and $4 \times 5 \mu \mathrm{l}$ were pipetted on the reflectors for total amounts of 10 and $200 \mathrm{ng}$ arsenic, respectively.

To estimate the influence of this damping for the LC analysis, samples were fitted using the $10 \mathrm{ng}$ and the $200 \mathrm{ng}$ As(V) standard spectra (Fig. 4). The differences in

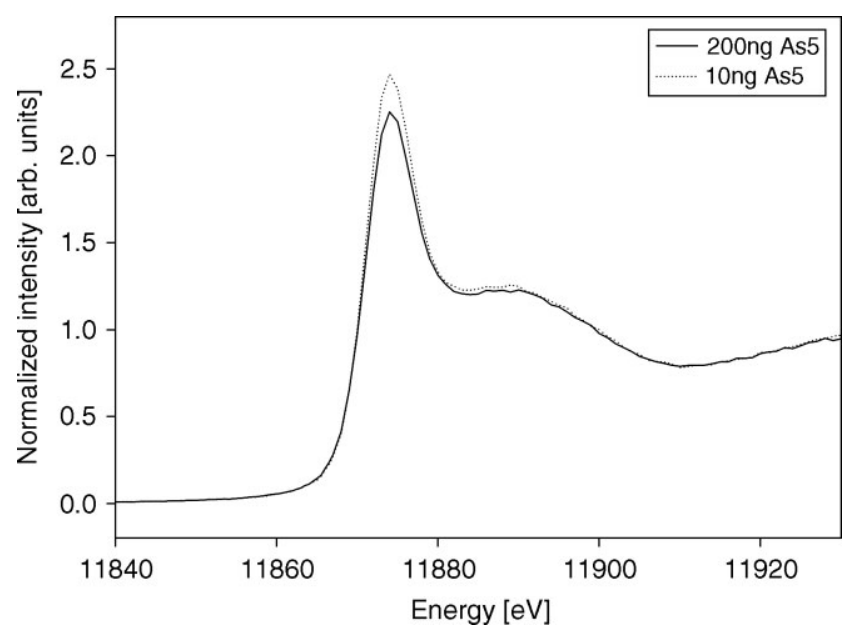

Figure 4. Arsenic K-edge XANES spectra for different total amounts of arsenate. 
the determination of the $\mathrm{As}(\mathrm{V}) / \mathrm{As}(\mathrm{III})$ ratio were found to be $<3 \%$ for xylem sap samples and in the range of $1 \%$ for nutrient solutions. Both values are smaller than the estimated uncertainties of the LC analysis because of measurement statistics.

The damping of the white line could be explained by self-absorption effects due to the TXRF geometry. In this geometry the path length of the incident beam in the droplet is longer than in other geometries and therefore its absorption in the sample cannot be ignored for larger amounts of concentrated samples. The self-absorption effect concerning surface analysis with x-ray absorption fine structure measurements in grazing incidence geometry has been studied by various authors. ${ }^{6,33,34}$ However, the investigations did not consider droplet sample geometries. Therefore, this topic needs further investigation and is currently being studied by our group.

\section{CONCLUSIONS}

It can be concluded that SR-TXRF offers good sensitivity for XANES speciation of chemical elements present in droplet samples at trace element levels. It could be demonstrated that a speciation of As is possible down to the $30 \mathrm{ng} / \mathrm{ml}$ level with this method. Repetitive measurements showed high reproducibility and no alteration of the oxidation state of the samples during the measurements. Owing to the grazing incidence geometry, self-absorption effects for droplet samples with high concentrations have to be considered, which will be further investigated. This may lead to a further improvement of the analysis of the TXRF-XANES spectra.

The presented data shows that cucumber plants treated with arsenate in concentrations of $150 \mathrm{ng} / \mathrm{ml}$ convert $\mathrm{As}(\mathrm{V})$ to As(III). A quantification of this effect reveals almost no difference in the ratio of $\mathrm{As}(\mathrm{V})$ to $\mathrm{As}(\mathrm{III})$ in the xylem sap of plants treated with nutrient solutions containing these two arsenic species. The presence of $\mathrm{As}(\mathrm{V})$ in the xylem sap of plants treated with $\mathrm{As}(\mathrm{III})$-containing nutrient solution suggests a partial oxidation of $\mathrm{As}(\mathrm{III})$ to $\mathrm{As}(\mathrm{V})$ in the nutrient solution before uptake. This suggestion could be confirmed as an analysis of the $\mathrm{As}$ (III)-containing nutrient solutions revealed a partial oxidation of $\mathrm{As}(\mathrm{III})$ to $\mathrm{As}(\mathrm{V})(<30 \%$ after $48 \mathrm{~h})$.

All results concerning arsenic speciation in xylem saps and nutrient solutions are in good agreement with those obtained by HPLC-HR-ICP-MS. ${ }^{15}$ This indicates the competitive capability of SR-TXRF XANES for trace element speciation.

\section{Acknowledgements}

This work was supported by the Austrian Science Fund (FWF), project number P18299, and the European Commission, project number II-20042060.

\section{REFERENCES}

1. Wobrauschek $\mathrm{P}$, Kregsamer $\mathrm{P}$, Ladisich $\mathrm{W}$, Streli C, Pahlke $\mathrm{S}$, Fabry L, Garbe S, Haller M, Knochel A, Radtke M. Nucl. Instrum. Methods Phys. Res., Sect. A 1995; 363(3): 619.
2. Wobrauschek P, Gorgl R, Kregsamer P, Streli C, Pahlke S, Fabry L, Haller M, Knochel A, Radtke M. Spectrochim. Acta, Part B 1997; 52(7): 901.

3. Pepponi G, Wobrauschek P, Streli C, Zöger N, Hegedüs F. X-Ray Spectrom. 2001; 30(4): 267.

4. Streli C, Pepponi G, Wobrauschek P, Jokubonis C, Falkenberg G, Zaray G. X-Ray Spectrom. 2005; 34(5): 451.

5. Falkenberg G, Pepponi G, Streli C, Wobrauschek P. Spectrochim. Acta, Part B 2003; 58(12): 2239.

6. Kawai J, Hayakawa S, Kitajima Y, Gohshi Y. Spectrochim. Acta, Part B 1999; 54(1): 215.

7. Baur K, Brennan S, Pianetta P, Opila R. Anal. Chem. 2002; 74: 609A.

8. Norman D. J. Phys. C: Solid State Phys. 1986; 19(18): 3273.

9. Pepponi G, Beckhoff B, Ehmann T, Ulm G, Streli C, Fabry L, Pahlke S, Wobrauschek P. Spectrochim. Acta, Part B 2003; 58(12): 2245.

10. Webb SM, Gaillard JF, Ma LQ, Tu C. Environ. Sci. Technol. 2003; 37(4): 754.

11. Smith PG, Koch I, Gordon RA, Mandoli DF, Chapman BD, Reimer KJ. Environ. Sci. Technol. 2005; 39(1): 248.

12. Castillo-Michel H, Parsons JG, Peralta-Videa JR, MartinezMartinez A, Dokken KM, Gardea-Torresdey JL. Plant Physiol. Biochem. 2007; 45(6-7): 457.

13. Osán J, Török B, Török S, Jones KW. X-Ray Spectrom. 1997; 26(1): 37.

14. Goodarzi F, Huggins FE. Energy Fuels 2005; 19(3): 905.

15. Mihucz V, Tatár E, Virág I, Cseh E, Fodor F, Záray G. Anal. Bioanal. Chem. 2005; 383(3): 461.

16. Bissen M, Frimmel FH. Acta Hydrochim. Hydrobiol. 2003; 31(1): 9.

17. Chen R, Smith BW, Winefordner JD, Tu MS, Kertulis G, Ma LQ. Anal. Chim. Acta 2004; 504(2): 199.

18. Meharg AA, Hartley-Whitaker J. New Phytol. 2002; 154(1): 29.

19. Ullrich-Eberius CI, Sanz A, Novacky AJ. J. Exp. Bot. 1989; 40(1): 119.

20. Czech V, Mihucz VG, Czövek P, Cseh E, Záray G. Met. Ions Biol. Med. 2006; 9: 158.

21. Meharg AA, Macnair MR. J. Exp. Bot. 1992; 43(4): 519.

22. Kertulis GM, Ma LQ, MacDonald GE, Chen R, Winefordner JD, Cai Y. Environ. Exp. Bot. 2005; 54(3): 239.

23. Gasparics T, Mihucz VG, Tatar E, Zaray G. Microchem. J. 2002; 73(1-2): 89.

24. Varsányi I, Fodré Z, Bartha A. Environ. Geochem. Health 1991; 13(1): 14

25. World-Health-Organization. Guidelines for drinking-water Quality, [electronic resource]. incorporating first addendum. vol. 1, Recommendations. -3rd edn. The Who website. 2007.; http: //www.who.int/water-sanitation-health/dwq/ gclwq3rev/en/index.html. Accessed 11 July 2007.

26. Streli C, Pepponi G, Wobrauschek P, Jokubonis C, Falkenberg G, Zaray G, Broekaert J, Fittschen U, Peschel B. Spectrochim. Acta, Part B 2006; 61(10-11): 1129.

27. The SII Nanotechnology Incorporated Website. 2007; www.radiantdetectors.com/vortex.html [11 July 2007].

28. Falkenberg G. Characterization of a Radiant Vortex Silicon Multi-Cathode X-ray Spectrometer for (Total Reflection) X-ray Fluorescence Applications, Hasylab Annual Report 2004, 2005. The HASYLAB Website. 2007. http: //hasyweb.desy. de/science/annual.reports/2005-report.

29. The IAEA Website. 2007; www.iaea.or.at/programmes/ripc/ physics/faznic/qxas.htm [11 July 2007].

30. The IFEFFIT Website. 2007; http://cars9.uchicago.edu/ifeffit/ [11 July 2007]

31. Newville M. J. Synchrotron Radiat. 2001; 8(2): 322.

32. Ravel B, Newville M. J. Synchrotron Radiat. 2005; 12(4): 537.

33. Tröger L, Arvanitis D, Baberschke K, Michaelis H, Grimm U, Zschech E. Phys. Rev. B 1992; 46(6): 3283.

34. Pfalzer P, Urbach JP, Klemm M, Horn S, denBoer ML, Frenkel AI, Kirkland JP. Phys. Rev. B 1999; 60(13): 9335. 